\title{
The Prevalence of Alcohol and Substance Use Among Medical Students at The Faculty of Medicine, Prince of Songkla University, 2016
}

Jarurin Pitanupong, M.D., Ornpailin Ratanapinsiri, M.D.

Department of Psychiatry, Faculty of Medicine, Prince of Songkla University, Hat Yai, Songkhla 90110, Thailand.

Received 28 August 2017 • Accepted 13 November 2017 • Published online 24 May 2018

\section{Abstract:}

Objective: To study the prevalence of alcohol and substance use among medical students.

Material and Methods: A cross-sectional study surveyed Prince of Songkla University medical students in 2016. Questionnaires for demographic data, the Alcohol Use Disorder Identification Test (AUDIT), experience with alcohol and substance abuse, and the Patient Health Questionnaire-9 Thai version (PHQ-9) were used. We analyzed the data in order to describe the behavior of subjects by descriptive statistics. The factors associated with alcohol used were analyzed by chi-square test and logistic regression.

Results: Seven hundred thirty-nine $(70.1 \%)$ of medical students completed the questionnaires. Participants, $56.0 \%$ were female and $44.0 \%$ were male. Mean age was 21.2 years old; 53.3\% have drunk alcohol; the gender proportion of drinkers was $60.0 \%$ of males and $48.1 \%$ of females. By AUDIT, $23.1 \%$ of medical students were high-risk drinkers. The most common reason for alcohol consumption was social engagement $(91.9 \%)$ and the most common reason for not drinking was having knowledge about the harmful health effects of alcohol (51.2\%). Of the medical students, 7.6\% had experience with substance use. The drugs most commonly used were cigarettes (5.3\%) and baraku (4.6\%). According to the PHQ-9, $11.2 \%$ of all medical students, $12.6 \%$ in males and $10.1 \%$ in females had depression. However, these high levels of depression did not associate with a high-risk of alcohol consumption. The significant factors that associated with high-risk drinking were gender [odd ratio $(O R)=1.9(1.1-3.4)$ ] and experience with substance use $[\mathrm{OR}=3.8(2.0-7.3)]$.

Conclusion: Half of medical students drank alcohol and approximate 1 in 10 had experience with substance use. Gender and experience with substance use were the significant factors that correlated with high-risk drinking.

Keywords: drinking alcohol, epidemiology, medical students, prevalence, substance use, trends

Contact: Assoc. Prof. Jarurin Pitanupong, M.D.

Department of Psychiatry, Faculty of Medicine, Prince of Songkla University,

Hat Yai, Songkhla 90110, Thailand.

E-mail: pjarurin@medicine.psu.ac.th
JHSMR 2018;36(2):107-115 www.jhsmr.org 


\section{Introduction}

Chronic stress among medical students affects their academic performance and leads to depression, addictive substance use and suicide. ${ }^{1}$ Several studies have examined the prevalence of alcohol intake or misuse in medical students., ${ }^{2,3}$ One study found that the prevalence of alcohol use among senior medical students in 23 medical schools was $87.5 \%,{ }^{4}$ in first, second, and third-year medical students it was $91.8 \%,{ }^{5} 86.0 \%{ }^{2}$ and $95.0 \%,{ }^{5}$ respectively. In Western countries, the study found that the percentage of students who are current drinkers rose between 1973, 1990 and 2002 (p-value<0.05). This rise was seen predominantly in females. The mean weekly consumption and mean number of units consumed in the past month rose between 1990 and 2002. This rise was seen in both males $(p-$ value $<0.010)$ and females $(p-$ value $<$ 0.001). ${ }^{3}$

In the United Kingdom, 45.0\% of 194 first-year medical students reported drinking experiences. There were significant positive associations between alcohol consumption and experiences such as missing class, becoming more sexually active, and getting into a physical fight or argument. ${ }^{6}$ There were also significant positive associations between the personality characteristic of psychoticism, ${ }^{6,7}$ or depression ${ }^{8-10}$ and alcoholism.

In Southern Iran, $22.0 \%$ of the male and $8.0 \%$ of the female medical students had a history of at least one episode of substance abuse. Of the students surveyed, $12.5 \%$ reported using substances occasionally and $8.0 \%$ reported using substances regularly. The most important motivator for beginning substance usage was curiosity $(59.7 \%)$, pleasure seeking (19.2\%), release of tension (8.9\%) and depression $(1.3 \%){ }^{11}$

In 2015, a cross-sectional survey conducted on a sample of 329 medical students at Jimma University reported that the current prevalence of stress was $52.4 \%$.
Academic related stress was the main source of stress among 281 (88.6\%) students. The prevalence of stress was high during the initial three years of study. Stress was a significant problem among medical students but had a negative correlation with academic achievement. Year of study, income, and substance use were associated with stress. ${ }^{1}$ In medical students with addiction, stress was significantly associated with alcohol intake [adjusted odds ratio $(O R)=1.9,95 \%$ confidence interval $(C l)=1.0-3.6]$.

In 2005, a study surveying the prevalence of drinking problems among medical students at Khon Kaen University, Thailand found that $6.4 \%$ of medical students had a drinking problem, $1.6 \%$ of medical students were hazardous drinkers, $2.6 \%$ of medical students were harmful use and $2.4 \%$ of medical students were alcohol dependent. The number of medical students that had a history of drinking was associated with academic year and gender. ${ }^{12}$

In 2015, a cross-sectional study surveying all medical students at the Faculty of Medicine, Prince of Songkla University found $26.6 \%$ had a history of drinking. History of drinking was significantly associated with happiness status. However, this study did not investigate other addictive substance use or other associated factors of alcohol and addictive substance use. ${ }^{13}$

The previous study did not survey about other addictive substance use or other associated factor of alcohol use so the insight study of prevalence and associated factors of alcohol used would lead to applied knowledge for prevention alcoholism problem among Prince of Songkla University's medical students and enhancement of their awareness of the problem.

\section{Objective}

1. To study the prevalence of alcohol and substance use among medical students. 
2. To study the associated factors of alcohol use in medical students.

\section{Material and Methods}

\section{Ethical consideration}

This study was approved by the Ethics Committee of the Faculty of Medicine, Prince of Songkla University (REC: 59-391-03-4).

\section{Study design}

Cross-sectional study conducted in order to survey the data of medical students from March to June 2017.

\section{Population}

One-thousand and fifty-five medical students categorized by academic year as follows: 194 persons from $1^{\text {st }}$ year, 176 persons from $2^{\text {nd }}$ year, 190 persons from $3^{\text {rd }}$ and $5^{\text {th }}$ year, 133 persons from $4^{\text {th }}$ year and 172 from $6^{\text {th }}$ year.

\section{Inclusion and exclusion criteria}

Inclusion criterion was medical students currently studying in the Faculty of Medicine, Prince of Songkla University, 2016.

Exclusion criterion was medical students who could not complete the questionnaire.

\section{Methodology}

A research assistant contacted the medical students in class, assured that their identities would be protected and all the participants retained the right to withdraw from the research at any time. The medical students considered whether to participate in the study or not then research assistant distributed self rating questionnaires. There were 2 options for submitting the questionnaire, place it in the wrapped box at the front of the classroom or drop it in a wrapped box located at the psychiatry department at a later time. Thus, participant confidentiality was protected.

\section{Instruments}

The questionnaire comprised 4 parts. (1) Demographic characteristics included age, academic year, religious preference, cumulative grade point average (GPA), hometown, parental marriage status, income and underlying disease. (2) The alcohol use disorder identification test (AUDIT): a 10-item screening tool. The minimum and maximum scores were 0-4 for each question. The cut-off score was $\geq 8$ with $0.95 \%$ sensitivity and $0.80 \%$ specificity. ${ }^{14}$ The score was $<8$, it indicated low-risk drinker. If the score was $\geq 8$, it indicated a hazardous drinker (8-15) or harmful user (16-19) or alcohol dependence $(\geq 20) .{ }^{15}$ (3) Experience with alcohol and substance use consisted of 4 questions. (4) Patient health questionnaire-9 Thai version (PHQ-9), which consisted of 9 questions, with a 4-rating Likert Scale for evaluating depression. The minimum and maximum scores were 0-4 for each question. The cut-off score was $\geq 9$ with $84.0 \%$ sensitivity, $77.0 \%$ specificity, $21.0 \%$ positive predictive value and $99.0 \%$ negative predictive value. The internal consistency reliability was assessed with Cronbach's alpha of 0.79 0.87 . $^{15}$ When the score was $\geq 9$, it indicated depression. ${ }^{16}$

\section{Statistical analysis}

All data were analyzed in order to describe the behavior of the sample using the descriptive statistic method. The results are presented as a frequency, percentage, average, standard deviation, median and interquartile range. The associated factors of alcohol use were analyzed by chi-square test and logistic regression. 


\section{Results}

\section{Demographic data}

The total number of medical students participating in this study was 739 persons and the response rate was $70.1 \%$. Among the participants, there were 414 females (56.0\%) and 325 males (44.0\%), (Table 1). Mean cumulative grade point average (GPA) was $3.5 \pm 0.3$ and medain income (interquartile range) was 8,000 (6,00010,000) Baht per month.

Table 1 Demographic characteristics $(n=739)$

\begin{tabular}{ll}
\hline Demographic characteristics & Number $(\%)$ \\
\hline Gender & \\
Male & $325(44.0)$ \\
Female & $414(56.0)$ \\
Academic year & \\
$1^{\text {st }}$ year medical student & $175(23.7)$ \\
$2^{\text {nd }}$ year medical student & $149(20.2)$ \\
$3^{\text {rd }}$ year medical student & $103(13.9)$ \\
$4^{\text {th }}$ year medical student & $123(16.6)$ \\
$5^{\text {th }}$ year medical student & $88(11.9)$ \\
$6^{\text {th }}$ year medical student & $101(13.7)$ \\
Religion & \\
Buddhism & $648(87.7)$ \\
Islam & $43(5.8)$ \\
Christianity & $16(2.2)$ \\
Others & $7(0.9)$ \\
No answer & $25(3.4)$ \\
Hometown & \\
Songkhla & $288(39.0)$ \\
Others & $434(58.7)$ \\
No answer & $17(2.3)$ \\
Parental marriage status & \\
Married & $647(87.6)$ \\
Divorced & $26(3.5)$ \\
Separated & $43(2.6)$ \\
Father or mother passed away & $4(0.5)$ \\
\hline No answer & \\
\hline & \\
\hline & \\
\hline
\end{tabular}

Table 1 (continued)

\begin{tabular}{ll}
\hline Demographic characteristics & Number (\%) \\
\hline Underlying disease & $637(86.2)$ \\
No & $93(12.6)$ \\
Yes & $9(1.2)$ \\
No answer & \\
Screening results for depression by PHQ-9 & $641(86.7)$ \\
No depression & $83(11.2)$ \\
Depression & $15(2.1)$ \\
No answer & $28(16.0)$ \\
Depression categorized by academic year & $26(17.5)$ \\
$1^{\text {st }}$ year medical student & $9(8.7)$ \\
$2^{\text {nd }}$ year medical student & $2(1.6)$ \\
$3^{\text {rd }}$ year medical student & $14(15.9)$ \\
$4^{\text {th }}$ year medical student & $4(3.9)$ \\
$5^{\text {th }}$ year medical student & \\
$6^{\text {th }}$ year medical student & $41(49.4)$ \\
Depression categorized by gender & $42(50.6)$ \\
Male $^{\text {Female }}$ &
\end{tabular}

PHQ-9=Patient Health Questionnaire-9

\section{Alcohol consumption}

The prevalence of drinking among medical students was 394 persons (53.3\%), 195 males (26.4\%) and 199 females (26.9\%). The gender proportion of drinkers was $60.0 \%$ in males and $48.1 \%$ in females. The mean age of drinkers was $17.7 \pm 2.1$ years old. The majority groups of drinkers were $1^{\text {st }}$ and $2^{\text {nd }}$ academic year medical students $(24.9 \%, 19.3 \%)$ (Table 2).

Among the drinking groups, the most common reasons for drinking were social engagement (91.9\%) and just trying it or curiosity (81.0\%). But some medical students used alcohol for stress relief (41.6\%), to counter disappointment (32.0\%) and for self-medication of insomnia (9.6\%). While in the non-drinking groups, the most common 
reason for abstaining from alcohol was having knowledge about the harmful health effects (51.2\%).

The AUDIT questionnaire found $76.9 \%$ were lowrisk drinkers, whereas high-risk drinkers, that is hazardous drinkers, harmful drinkers and the alcohol dependence were $15.5 \%, 3.3 \%$ and $4.3 \%$, respectively (Table 2).

Table 2 Experience of drinking alcohol and substance abuse

\begin{tabular}{|c|c|}
\hline Substance use characteristics & Number $(\%)$ \\
\hline \multicolumn{2}{|c|}{ Frequency of drinking alcohol in 1 year } \\
\hline Never & $345(46.7)$ \\
\hline Have been using & $394(53.3)$ \\
\hline \multicolumn{2}{|l|}{ Severity $(n=394)$} \\
\hline Low risk drinker & $303(76.9)$ \\
\hline Hazardous drinker & $61(15.5)$ \\
\hline Harmful use & $13(3.3)$ \\
\hline Alcohol dependence & $17(4.3)$ \\
\hline \multicolumn{2}{|c|}{ Type of alcohol (more than 1 answer) } \\
\hline Beer & $287(72.8)$ \\
\hline Black liquor & $278(70.6)$ \\
\hline Wine & $227(57.6)$ \\
\hline Champagne & $189(48.0)$ \\
\hline White liquor & $42(10.7)$ \\
\hline \multicolumn{2}{|c|}{ At least 1 out of 6 substance abuse experiences } \\
\hline Never use & $615(83.2)$ \\
\hline Used to use & $56(7.6)$ \\
\hline No answer & $68(9.2)$ \\
\hline \multicolumn{2}{|l|}{ Academic year $(n=394)$} \\
\hline $1^{\text {st }}$ year medical student & $98(24.9)$ \\
\hline $2^{\text {nd }}$ year medical student & $76(19.3)$ \\
\hline $3^{\text {rd }}$ year medical student & $50(12.7)$ \\
\hline $4^{\text {th }}$ year medical student & 65 (16.5) \\
\hline $5^{\text {th }}$ year medical student & $47(11.9)$ \\
\hline $6^{\text {th }}$ year medical student & $58(14.7)$ \\
\hline
\end{tabular}

\section{Substance abuse}

The prevalence of other substances use (exclude benzodiazepines) among medical students was $7.6 \%$. The most common other substances used by medical students were cigarettes (5.3\%) and baraku (4.6\%) (Figure 1). Only 1 medical student (1.6\%) had ever used and still uses cannabis.

Among the substance abuse group, the reasons for using were just trying or curiosity (58.9\%) and social engagement $(35.7 \%)$, whereas the reasons for not using drugs were having knowledge about the harmful effect of substance abuse (78.0\%) and consequences (53.2\%).

\section{Depression screening}

According to the PHQ-9, $11.2 \%$ of all medical students (12.6\% in males and $10.1 \%$ in females) had depression. In fact, the majority of groups with depression were $1^{\text {st }}$ and $2^{\text {nd }}$ academic year medical students (Table 1 ).

\section{Associated factors related to alcohol use}

Variables whose $p$-values from the univariate analysis were lower than 0.2 were included in the chi-square test (Table 3). From the multivariate analysis, there were statistically significant associated factors related to alcohol consumption (Table 4). These factors were gender and history of substance use ( $p$-value<0.05). Using the OR, male medical students had a 1.9 greater risk of hazardous drinking, harmful drinking and alcohol dependence when compared with female medical students (95\% Cl=1.1-3.4). While medical students who had experience with substance use had a 3.8 greater risk of hazardous drinking, harmful drinking and alcohol dependence when compared with the non-using group (95\% Cl=1.9-7.3). However, a high level of depression did not associate with high risk level of alcohol consumption. 


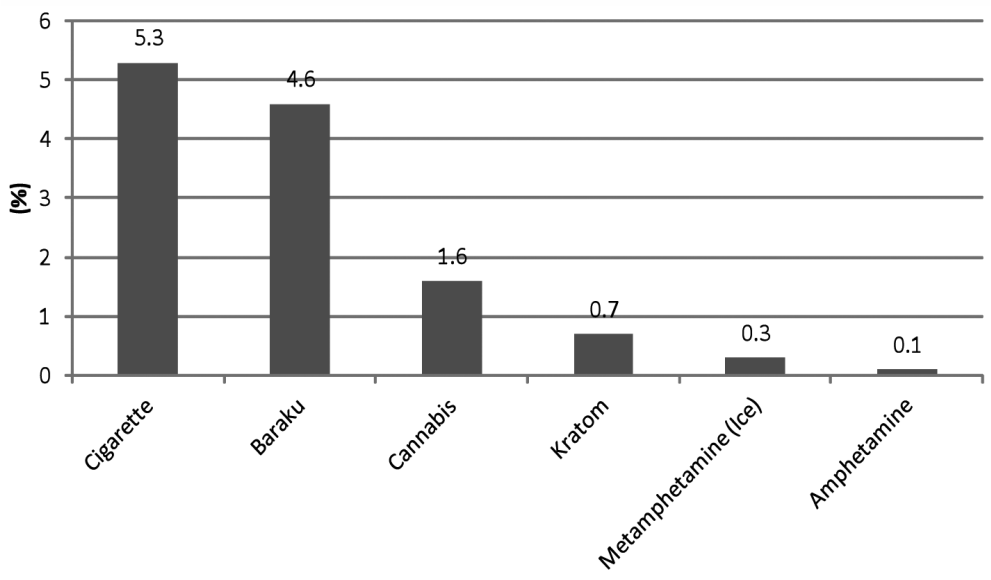

Ever used and still uses substance

Figure 1 Substance use

Table 3 Association between general characteristics and risk of drinking alcohol $(n=394)$

\begin{tabular}{llll}
\hline General characteristics & Risk $(\mathbf{n}=\mathbf{9 1})$ & No risk $(\mathbf{n}=\mathbf{3 0 3})$ & P-value \\
\hline Gender & & & \\
Male & $60(65.9)$ & $135(44.6)$ \\
$\quad$ Female & $31(34.1)$ & $168(55.4)$ & 0.001 \\
Academic year & & & \\
$1^{\text {st }}$ year medical student & $31(34.4)$ & $67(22.1)$ \\
$2^{\text {nd }}$ year medical student & $20(22.0)$ & $56(18.5)$ \\
$3^{\text {rd }}$ year medical student & $14(15.4)$ & $36(11.9)$ \\
$4^{\text {th }}$ year medical student & $11(12.1)$ & $54(17.8)$ \\
$5^{\text {th }}$ year medical student & $7(7.7)$ & $40(13.2)$ \\
$6^{\text {th }}$ year medical student & $8(8.8)$ & $50(16.5)$ \\
Religion & & $273(94.1)$ \\
Buddhism & $82(93.2)$ & $17(5.9)$ \\
Others & $6(6.8)$ & $122(40.3)$ \\
Cumulative GPA & & $118(38.9)$ \\
$<3.5$ & $46(50.5)$ & $63(20.8)$ \\
3.5-4.0 & $30(33.0)$ & $121(40.3)$ \\
No answer & $15(16.5)$ & $179(59.7)$ \\
Hometown & $36(40.4)$ & 0.941 \\
Songkhla & $53(59.6)$ & 0.217 \\
Others & &
\end{tabular}


Table 3 (continued)

\begin{tabular}{|c|c|c|c|}
\hline General characteristics & Risk ( $n=91)$ & No risk $(n=303)$ & P-value \\
\hline Hometown & & & 0.918 \\
\hline Songkhla & $36(40.4)$ & $121(40.3)$ & \\
\hline Others & $53(59.6)$ & $179(59.7)$ & \\
\hline Parental marriage status & & & 0.619 \\
\hline Married & $79(86.8)$ & $270(89.4)$ & \\
\hline Others & $12(13.2)$ & $32(10.6)$ & \\
\hline Income (Baht/per month) & & & 0.136 \\
\hline $1,000-9,999$ & $40(44.0)$ & $152(50.2)$ & \\
\hline$\geq 10,000$ & $37(40.7)$ & $90(29.7)$ & \\
\hline No answer & $14(15.4)$ & $61(20.1)$ & \\
\hline Underlying disease & & & 0.668 \\
\hline None & $74(83.1)$ & $258(85.7)$ & \\
\hline Present & $15(16.9)$ & $43(14.3)$ & \\
\hline Experience of substance abuse & & & $<0.001$ \\
\hline Never use & $55(67.9)$ & $245(91.1)$ & \\
\hline At least 1 out of 6 substance abuse experiences & $26(32.1)$ & $24(8.9)$ & \\
\hline Depression & & & 0.522 \\
\hline No depression & $75(85.2)$ & $262(88.5)$ & \\
\hline Depression & $13(14.8)$ & 34 (11.5) & \\
\hline
\end{tabular}

$\mathrm{p}$-value was based on chi-square test

GPA=grade point average

Table 4 Factors related to alcohol use

\begin{tabular}{llll}
\hline Factors & $\begin{array}{l}\text { Crude OR } \\
(95 \% \mathrm{Cl})\end{array}$ & $\begin{array}{l}\text { Adjusted OR } \\
(95 \% \mathrm{Cl})\end{array}$ & $\begin{array}{c}\text { P-value } \\
\text { LR-test }\end{array}$ \\
\hline $\begin{array}{l}\text { Gender } \\
\text { Female } \\
\text { Male }\end{array}$ & Reference & Reference & 0.020 \\
$\begin{array}{l}\text { Experience of substance abuse } \\
\text { Never use } \\
\text { At least } 1 \text { out of } 6 \text { substance abuse experiences }\end{array}$ & $2.6(1.5-4.4)$ & $1.9(1.1-3.4)$ & $<0.001$ \\
\hline
\end{tabular}

Multiple logistic regression, adjusted factors were gender, educational year, income and experience of substance abuse $\mathrm{OR}=$ odds ratio, $\mathrm{Cl}=$ confidence interval, $\mathrm{LR}=$ likelihood ratio 


\section{Discussion}

This study shows the current situation of alcohol and substance use among medical students at the Faculty of Medicine, Prince of Songkla University, 2016. Comparing with cross-sectional study at Faculty of Medicine, Prince of Songkla University in 2015, the prevalence of alcohol using among medical students tended to increase. The hugely different prevalence was $26.6 \%$ in 2015 and 53.3\% in 2016. Despite the same population, the reason for the difference might be the submitting options that participant confidentiality was protected.

The severity of alcohol problems among medical students tended to increase compared with Khon Kaen University's study in $2005,{ }^{12}$ which found that $6.4 \%$ of medical students had drinking problems whereas this study found $23.1 \%$ of medical students were high-risk drinkers. In this study, the majority groups of alcohol drinkers were $1^{\text {st }}$ and $2^{\text {nd }}$ academic year medical student, but the previous study showed that the majority groups were $4^{\text {th }}, 5^{\text {th }}$ and $6^{\text {th }}$ academic year medical students. In our opinion, the reasons that the majority groups of alcohol drinkers were in the pre-clinic group, might be (1) less responsibility, shorter duty period and more free time than in the clinic group. ${ }^{12}$ (2) alcohol drinking groups might have co-morbidity disorders, such as depression and used alcohol to self-medicate in order to relieve distress and suffering, ${ }^{13}$ and (3) a change in culture or the influence of social media on teenagers. ${ }^{3}$

Interesting data from this study, the gender proportion of drinking was $48.1 \%$ in females and $60.0 \%$ in males. That means the trend of drinking and female drinking in teenagers might be higher than in the past. And this trend looks similar to the prevalence data of Western countries, ${ }^{2,3}$ while the previous cross-sectional survey in Thailand among 50,033 high school college students between 2007 and 2008 found the prevalence rates of past-year drinking $25.5 \%$ in males and $14.5 \%$ in females. The reasons for excessive female drinking behavior might be life-style and the changing culture or using alcohol for stress reduction or self-medication of mood symptoms. ${ }^{13}$ However, male drinkers had a higher risk of alcohol consequences and dependence than the female drinkers. This representative results were the significantly considered evidences needed relevant to be reviewed in future research about drinking behavior and associated adverse health and social consequences among male and female medical students.

According to this study, $7.6 \%$ of medical students had experience with substance abuse. This prevalence was lower than in previous survey among high school student in Thailand between 2007 and 2008 that found the prevalence of smoking was 4.9-35.0\% and illicit substance use was $2.4-17.8 \%{ }^{17}$ But the most important motivations for engaging in substance abuse were the same as in other studies ${ }^{11}$ : curiosity (58.9\%), social engagement (35.7\%) and tension or anxiety releasing (19.6\%).

However, the alcohol consumption risk factors associated with previous substance abuse experiences and gender. Then the university policies and prevention programs should be reviewed and reformed for alcohol consumption and substance abuse behavior in medical students, especially among males and pre-clinic groups.

\section{Limitation}

The cross-sectional design of this study limited the results because cause-effect could not be inferred.

\section{Implication and future recommendation}

Prospective or meta-analysis studies are needed to determine the associated factors of prevalence of alcohol and substance use problems among medical students. Furthermore, a multicenter study should be conducted by medical schools in order to compare the differences between multi-cultural areas. 


\section{Conclusion}

Half of medical students drank alcohol and approximate 1 in 10 had experience with substance use. Gender, academic year and experience with substance use were the significant associated factors that associated with alcohol drinking. Prospective or meta-analysis studies are needed to find the associated factors of prevalence of alcohol and substance use problems among medical students.

\section{Acknowledgement}

The authors wish to thank all of the medical students who participated in this study. This research was supported by a grant from the Faculty of Medicine, Prince of Songkla University.

\section{References}

1. Melaku L, Mossie A, Negash A. Stress among medical students and its association with substance use and academic performance. J Biomed Educ 2015. Doi: 10.1155/2015/149509.

2. Pickard M, Bated L, Dorian M, Greig H, Saint D. Alcohol and drug use in second-year medical students at the University of Leeds. Med Educ 2000;34:148-50.

3. Boland M, Fitzpatrick P, Scallan E, Daly L, Herity B, Horgen J, et al. Trends in medical student use of tobacco, alcohol and drugs in Irish university, 1973-2002. Drug Alcohol Depend 2006;85:123-8.

4. Baldwin DC Jr, Hughes PH, Conard SE, Storr CL, Sheehan DV. Substance use among senior medical students: a survey of 23 medical schools. JAMA 1991;265:2074-8.

5. Croen LG, Woesner M, Herman M, Reichgott M. A longitudinal study of substance use and abuse in single class of medical students. Acad Med 1997;72:376-81.

6. Newbury BD, White M, Kamali F. Factors influencing alcoho and illicit drug use among medical students. Drug Alcohol Depend 2000;59:125-30
7. Forney MA, Ripley WK, Forney PD. A profile and prediction study of problem drinking among first-year medical students. Int J Addict 1988;23:767-79.

8. Tchen G, Carter A, Gibbons P, McLaughlin P. What is the relationship between indicators of stress and academic performance in first year university students? a prospective study. JIR 2001;40:463-73.

9. Rosenthal JM, Okie S. White coat, mood indigo depression in medical school. N Engl J Med 2005;353:1085-8.

10. Sreeramareddy CT, Shankar PR, Binu VS, Mukhopadhyay C, Ray B, Menezes RG. Psychological morbidity, sources of stress and coping strategies among undergraduate medical students of Nepal. BMC Med Educ 2007;7:26.

11. Sahraian A, Sharifian M, Omidvar B. Prevalence of substance abuse among the medical students in Southern Iran. Shiraz E Med J 2010;11:198-202.

12. Arunpongpaisal S, Rangsikachi P, Virasiri S. Prevalence of alcohol drinking problems among medical students at Khon Kaen University. J Psychiatr Assoc Thailand 2006;51:155-66.

13. Pitanupong J, Kanapikhu S. Happiness status and related factors among clinic medical students of Prince of Songkla University, 2015. Songkla Med J 2017;35:229-38.

14. Saunders JB, Aasland OG, Babor TF, de la Fuente JR, Grant M. Development of the Alcohol Use Disorders Identifiation Test (AUDIT): WHO collaborative project on early detection of persons with harmful alcohol consumption--II. Addiction 1993; 88:791-804.

15. Integrated Management for Alcohol Intervention Program. The alcohol use disorders identification test [homepage on the Internet]. Chiang Mai: Integrated Management for Alcohol Intervention Program; 2009 [cited 2016 Dec 2]. Available from: http://www.i-mapthailand.org/site/media/knowledge/ practitioners/audit_self_test.pdf

16. Lotrakul M, Sumrithe S, Saipanish R. Reliability and validity of the Thai version of the PHQ-9. BMC Psychiatry 2008;8:46.

17. Assanangkornchai S, Mukthong A, Intanont T. Prevalence and patterns of alcohol consumption and health-risk behaviors among high school students in Thailand. Alcohol Clin Exp Res 2009;33:2037-46. 